\title{
O "problema das seitas" e os periódicos: uma análise das representações sobre o movimento Hare Krishna nos jornais (1974-1984) ${ }^{1}$
}

The "sects problem" and the periodicals: a review on the Hare Krishna Movement's representations in the Newspapers (1974-1984)

Leon Adan Gutierrez de Carvalho ${ }^{2 *}$

\section{RESUMO}

Os primeiros membros do movimento Hare Krishna no Brasil chegaram em 1973 e, em Pernambuco, sua presença foi noticiada já no início de 1974, fazendo circular - não sem intencionalidades - determinadas representações acerca dos seus membros, suas práticas e visões de mundo. $\mathrm{O}$ presente trabalho analisa algumas dessas representações construídas pelos jornais, mais precisamente o Diario de Pernambuco, entre os anos de 1974 e 1984, buscando compreender os elementos discursivos que contribuíram para influenciar a opinião pública acerca dos "novos movimentos religiosos", como o Hare Krishna. Para tanto, se fez necessário utilizar autores como Roger Chartier e Michel de Certeau para uma compreensão do lugar social de onde partem os discursos e das representações produzidas por estes lugares. Pudemos perceber que o jornal buscou deslegitimar outras formas de religiosidade que se constituíam como "novas" diante do quadro tradicional religioso brasileiro, classificando-as como "seitas" que poderiam ser "perigosas" à sociedade.

Palavras-chave: Movimento Hare Krishna; Novos movimentos religiosos; Seitas; Representações.

\begin{abstract}
The first members of the Hare Krishna movement in Brazil arrived in 1973 and, in Pernambuco, its presence has been reported by newspapers in early 1974, publicizing not without intentions - certain representations about its members, their practices and worldviews. This paper examines some of these representations built by the newspapers, specifically, the Diario de Pernambuco, between the years 1974 and 1984, trying to understand the discursive elements that contributed to influence public opinion about "new religious movements", such as the Hare Krishna movement. Therefore, it was necessary to use authors such as Roger Chartier and Michel de Certeau to an understanding of the social place from where the discourses and representations take off and how they are made by these places. We could perceive that the newspaper sought to delegitimize other forms of religiosity that were constituted as "new" before the traditional Brazilian religious framework, classifying them as "sects" that could be "dangerous" to society.
\end{abstract}

Keywords: Hare Krishna movement; News religious movements; Sects; Representations.

\footnotetext{
${ }^{1} \mathrm{O}$ presente artigo é consequência das discussões realizadas em uma pesquisa de Dissertação de Mestrado concluída através do Programa de Pós-Graduação em História da Universidade Federal Rural de Pernambuco (UFRPE) em 2017. Agradecemos a CAPES pelo financiamento da bolsa de estudos durante o período da pesquisa.

${ }^{2}$ Mestre em História Social da Cultura Regional pela UFRPE e doutorando em História pela Universidade Federal do Paraná (UFPR), com bolsa CAPES.
} 


\section{Introdução}

A Sociedade Internacional para Consciência de Krishna (ISKCON), conhecida popularmente como movimento Hare Krishna, foi uma instituição fundada em 1966, na cidade de Nova Iorque, pelo indiano Bhaktivedhanta Swami Prabhupada, um guru ou mestre espiritual hindu. O movimento Hare Krishna pode ser caracterizado como um dos "novos movimentos religiosos"3 que despontaram no Ocidente na década de 1960, e, no Brasil, no início dos anos 1970.

O movimento Hare Krishna surgiu nos países ocidentais como algo inteiramente novo, como "uma das mais sólidas instituições religiosas de cunho orientalista não vinculada a grupos étnicos" (GUERRIERO, 2001), mas, apesar disso, sua tradição teológica não é nova e se relaciona a um dos ramos do Hinduísmo, o Vaishnavismo Gaudiya ${ }^{4}$. Assim, apesar de podermos classificar o Hare Krishna como um dos novos movimentos religiosos, devemos considerar que sua tradição "nãoocidental" é bem mais antiga.

A introdução do movimento Hare Krishna no Brasil estaria relacionada a outros fenômenos do gênero da década de 1970 que atraíam jovens das camadas médias urbanas interessados em um estilo de vida alternativo. Esse caminho escolhido incluía práticas como ioga, meditação, esoterismo, a busca pela vivência comunitária e novas formas de se relacionar com o sagrado (GUERRIERO, 2003). Os adeptos de movimentos como esse teriam em comum a procura por formas de religiosidade nãotradicionais, ao contribuir para um reencantamento do mundo, transformando a oferta religiosa em múltiplas formas e contrapondo as conhecidas teorias de dessacralização da sociedade.

O movimento da contracultura, iniciado nos anos 1960, nos Estados Unidos, tinha como objetivo criar um "mundo novo", mais igualitário, por meio da propagação

\footnotetext{
${ }^{3}$ O conceito de "novos movimentos religiosos" é impreciso e um tanto problemático já que alguns dos fenômenos e práticas classificados como tal não seriam exatamente "novos" (GIUMBELLI 2002, p. 17 24) - como o movimento Hare Krishna. É muito difícil incluir fenômenos tão diversos sobre uma mesma definição. Alguns, talvez, nem possam (ou não queiram) ser classificados como "religiosos" (como algumas práticas de ioga ou como a Cientologia, por exemplo). Alguns autores acabam utilizando uma definição genérica, como "todos os movimentos de cunho religioso ou espiritualista que tenham surgido no bojo do movimento de contracultura, após 1960" (GUERRIERO, 2006, p. 43). Por se tratar de um termo amplamente utilizado e discutido em estudos sobre religiões, iremos aplica-lo aqui por uma questão de convenção ou por falta de um termo mais específico, mas, levaremos em consideração a crítica e os limites do conceito.

${ }^{4}$ Essa tradição, que ficou conhecida como Vaishnavismo Gaudiya, foi estabelecida na Bengala (Índia) no século XVI pelo místico Chaitanya Mahaprabhu (1486-1534) e por seus seguidores, constituindo-se como uma tradição de cunho teísta tendo a divindade Krishna como Deus Supremo (Cf. BRYANT; EKSTRAND, 2004, p. 1-2).
} 
do amor, da paz, e da quebra dos costumes, padrões da sociedade judaico-cristã, tradições e preconceitos ocidentais, ou seja, rejeitando os valores tradicionais que então reprimiam e alienavam a individualidade e a autonomia. Os contraculturais acreditavam que não bastava transformar a estrutura econômica e o Estado. Era preciso mudar a própria maneira de se comportar, sentir e muito disso se deu através de uma "nova forma de consciência religiosa" (DUARTE, 2010). Esse movimento teria aberto espaço para essas formas de religiosidade, todavia, com seu declínio, essas iniciativas alternativas teriam encontrado sua própria via de continuidade (GUERRIERO, 2001, p. 46-50).

Os primeiro membros a aderirem à ISKCON nos Estados Unidos e, de certa forma, na Europa e América Latina, teriam vindo de simpatizantes da contracultura que conferiram à instituição a "espontaneidade" característica dos primeiros anos de sua atuação.

Enquanto movimento religioso, a ISKCON possui uma teologia que se fundamenta tanto na prática individual (através do canto ou meditação) quanto na prática missionária, em uma tentativa prosélita de ofertar ao seu público-alvo o processo de devoção à Krishna. Essa divindade é vista sob uma perspectiva teísta, sendo o Deus supremo, criador, onipotente e onisciente. A principal prática de um devoto Hare Krishna é o canto (individual e coletivo) do mantra (hino) Hare Krishna ${ }^{5}$, além da leitura e difusão da literatura traduzida e comentada pelo seu fundador, Prabhupada.

No Brasil e em Pernambuco, os primeiros membros do movimento Hare Krishna surgiram em 1973 e, a partir de 1974, jornais, como o Diario de Pernambuco (DP) ${ }^{6}$, dedicaram algumas de suas páginas a construir representações sobre o movimento Hare Krishna, influenciando e sendo influenciados pela opinião pública, ao revelar, assim, os interesses das mídias impressas em selecionar e solidificar determinadas imagens sobre os novos movimentos religiosos, como o Hare Krishna ${ }^{7}$.

O DP era o jornal mais influente do Estado, com a maior tiragem número de páginas, e "o mais antigo em circulação da América Latina", como diria, orgulhosamente, o slogan estampado em todas as suas edições. O jornal pertence, desde

\footnotetext{
5 O mantra Hare Krishna é composto dos seguintes versos: Hare Krishna, Hare Krishna, Krishna Krishna, Hare Hare / Hare Rama, Hare Rama, Rama Rama, Hare Hare,

${ }^{6}$ Iremos abreviar o nome do jornal, incluindo nas referências ao longo do texto, para facilitar a leitura. O nome próprio "Diario" não possui acentuação e, assim, mantemos aqui a forma original da escrita.

${ }^{7}$ De forma semelhante, outros jornais brasileiros do período abordariam o tema do surgimento e desenvolvimento do movimento Hare Krishna - de suas práticas e seus representantes. Mas é assunto para uma pesquisa ainda em andamento sobre o movimento Hare Krishna e a imprensa no Brasil.
} 
1931, aos Diários Associados, grupo midiático fundado por Assis Chateaubriand. Podemos dizer que o DP assume o peso de sua tradição e, assim, no período a que nos referimos, muitos temas (como as religiões, por exemplo) eram tratados com o intuito de valorizar o que seria considerado "tradicional". É válido lembrar, ainda, a forte censura promovida pelo regime ditatorial civil-militar nessa época que favorecia a publicação de reportagens de forte teor moral.

Para uma análise de fontes jornalísticas, é importante compreender que, “independente do jornal, o pesquisador que utiliza esse periódico como fonte não deve perder de vista que o mesmo nunca deve ser tomado com efeito de verdade, mas sim como representação de grupos sociais sobre si mesmos e a realidade que os cercam" (FRANCO; SILVA, 2010, p. 10).

Segundo Roger Chartier (2002, p. 19), a análise das representações coletivas nos permite visualizar como os diferentes atores sociais traduzem suas posições e interesses objetivamente confrontados, descrevendo paralelamente a sociedade tal como pensam que ela é ou como gostariam que fosse. Para o autor, a análise das representações visa “[...] compreender os mecanismos pelos quais um grupo impõe, ou tenta impor, a sua concepção do mundo social, os valores que são seus, e o seu domínio", dispostos em termos de poder e dominação (CHARTIER, 2002 p. 17). Seguindo por essa senda teórica, analisamos, neste artigo, aspectos de uma história das representações do movimento Hare Krishna, tendo como fonte principal o jornal DP.

Na década de 1970, em pleno processo de expansão pelo mundo, o movimento Hare Krishna chegou à Região Metropolitana do Recife que constituía um dos principais centros urbanos do país. Apesar de alguns praticantes do Hare Krishna terem tentado instalar um templo nessa região em 1974 (que não teve uma continuação sistemática), foi só no ano de 1977 que membros enviados oficialmente pela ISKCON chegaram à cidade para abrir um templo da instituição.

Depois do templo de Recife, vários outros foram abertos em capitais do Nordeste e Norte do país. Mais tarde esse centro de irradiação do movimento seria transferido para a principal comunidade da ISKCON no Norte e Nordeste, a Fazenda Nova Vraja Dhama (Caruaru-PE), fundada em 1987 (CARVALHO, 2014; 2017b). A partir desse estado que o movimento se solidificou em uma ampla região do país, entre as décadas de 1970 e 1980, configurando uma relevância do espaço pernambucano para a história das práticas e representações do Hare Krishna no Brasil. 
O antropólogo Silas Guerriero (2001), um dos primeiros e mais importantes acadêmicos estudiosos do Hare Krishna no Brasil $^{8}$, classifica a evolução do movimento no país em três etapas: a primeira fase teria ocorrido entre 1974 e 1977 e marcaria o período de pioneirismo e estabelecimento da ISKCON, culminando com o ano da morte do seu fundador, Swami Prabhupada; o segundo momento seria entre 1978 e os anos 1990, caracterizado pela rápida expansão da instituição, do estabelecimento de templos nas principais capitais do país e pela difusão de suas ideias através da distribuição de livros e dos cânticos em público; e o terceiro momento, dos anos 1990 aos dias atuais, marcado por diversas mudanças dentro da instituição que levariam a um processo de acomodação e inserção no campo das demais denominações religiosas ${ }^{9}$.

Em nosso caso, analisaremos adiante as representações construídas em duas fases do movimento Hare Krishna na Região Metropolitana do Recife: a primeira entre 1974-1978 e a segunda entre 1978 e 1984 - período em que notaremos a consolidação local do movimento e, consequentemente, uma preocupação constante de determinados atores sociais em analisar, confrontar e julgar as práticas, os membros e as instituições dos novos movimentos religiosos, predominantemente denominados como "seitas"10.

A caracterização dos novos movimentos religiosos como "seitas" e de suas práticas como "lavagem cerebral" causou conflitos constantes nos Estados Unidos, em países da Europa e América Latina. Nas discussões dos jornais, podemos notar as famílias, indivíduos e instituições que se posicionavam contrários às, assim chamadas, "seitas". De um lado, aqueles que utilizavam desse discurso para construir uma

\footnotetext{
${ }^{8}$ Existem poucos estudos sobre o movimento Hare Krishna no Brasil na área das Ciências Sociais. Entre os mais sólidos, podemos citar os de Guerriero (1989; 2001); Silveira (2000); e Adami (2013); até onde pudemos constatar, nossa pesquisa sobre a temática tem sido a única em termos sistemáticos na área de História. Cf. Carvalho (2014; 2017a; 2017b).

${ }^{9}$ Apesar de Guerriero definir a data de início do movimento Hare Krishna no Brasil em 1974, no nosso trabalho (CARVALHO, 2017a) constatamos, através de fontes jornalísticas, que os primeiros devotos Hare Krishna surgiram no país (incluindo em Pernambuco) em 1973.

${ }^{10}$ Entre os grupos classificados como "seitas" estariam movimentos de inspiração nas tradições e na espiritualidade hindu, como o Hare Krishna, Ananda Marga, Brahma Kumaris, Meditação Transcendental, discípulos de Rajneesh e outros gurus; entre os adeptos de grupos inspirados em outras doutrinas orientais estariam a Seicho-No-Ie, Aun Shinrikyo, Igreja Messiânica Mundial, Soka Gakkai; entre os movimentos de inspiração cristã estariam englobados a Igreja da Unificação (do Reverendo Moon), os Meninos de Deus (conhecidos depois como "A família") e as milenaristas Igreja Adventistas do Sétimo Dia, Testemunhas de Jeová e a Igreja de Jesus Cristo dos Santos dos Últimos Dias (Mórmons). Essas são somente algumas. Fica evidente a enorme diferença entre as instituições e as teologias que elas procuram representar, tornando difícil agrupar todas sob um mesmo guarda-chuva conceitual como "seitas". Ainda assim, havia uma generalização do uso do termo "seita" para se referir a todos esses grupos que teriam como característica em comum, o fato de serem religiões ou instituições religiosas minoritárias no Brasil.
} 
determinada representação desses movimentos e, de outro, os adeptos dos novos movimentos religiosos (e suas instituições) que tentavam configurar as suas autorrepresentações, gerando, assim, as "lutas de representações" que foram travadas no período. Segundo Chartier (2002):

As lutas de representações têm tanta importância como as lutas econômicas para compreender os mecanismos pelos quais um grupo impõe, ou tenta impor, a sua concepção do mundo social, os valores que são seus, e o seu domínio. Ocupar-se dos conflitos de classificações ou de delimitações não é, portanto, afastar-se do social - como julgou durante muito tempo uma história de vistas demasiado curtas -, muito pelo contrário, consiste em localizar os pontos de afrontamento tanto mais decisivos quanto menos imediatamente materiais. (CHARTIER, 2002, p. 17).

Não era incomum que os jornais utilizassem a dicotomia "igreja/seita" para diferenciar as religiões cristãs (e mais completamente, o Catolicismo) das outras formas de religiosidade tidas como "seitas", como se os "novos movimentos religiosos" não fossem válidos ou nem fundamentados. Boa parte da utilização dos discursos que "batizaram" uma determinada prática religiosa como "seita" o fizeram em um sentido de servir-se de um "instrumento de luta religiosa, ideológica e política", efetuando uma simplificação e um reducionismo intencional à complexidade do fenômeno religioso (PARKER, 1997, p. 79).

Segundo Cristian Parker (1997, p. 79, 89), o conceito de "seita" era inicialmente usado para designar as heresias cristãs no medievo e que mais tarde passou a ser uma definição sociológica na tipologia "igreja-seita" na obra de sociólogos como Troeltsch. Porém, ao - basear-se na sua eclesialidade de tradição cristã, a ideia de "seita" se degenerou em um conceito ideológico, sendo assim, é incongruente considerar como "seita" expressões de religiões orientais como o movimento Hare Krishna.

Dessa forma, tomaremos expressões como "seita", "lavagem cerebral", etc, como ideológicos, pejorativos, depreciativos, cuja utilização em veículos de informação como os jornais, produziam intencionalmente representações de um "outro" que precisam ser problematizadas. Faremos uma breve análise de questões como essas a seguir. 


\section{De religião "oriental" a "seita": representações sobre os primeiros momentos do movimento Hare Krishna em Pernambuco}

No início de 1974, adeptos do movimento Hare Krishna chegaram à Região Metropolitana do Recife na tentativa de estabelecer ali um "templo". Rapidamente, os jornais relataram a novidade. As características de seus membros e de suas práticas, tidas como "exóticas", chamaram a atenção da imprensa.

Na primeira reportagem sobre o movimento no DP havia um relato da presença dos religiosos no Bairro Novo, em Olinda, no que seria um "templo" instalado em uma "casa de praia" na Rua Pedro de Assis Rocha. Segundo a reportagem, os rapazes levavam "muito a sério a sua religião", seriam "jovens", "alegres" e fariam "questão de dizer que nada tem a ver (sic) com os "hippies" "11. Nessa reportagem, de tom bastante amistoso e curioso em relação à novidade, o Hare Krishna é tido como "religião", "religião de origem indu" (sic) ou "religião indu" (sic) e ainda traça uma explicação sobre aquilo que seria necessário àqueles que quiserem "seguir a religião", evidenciando o caráter de disponibilidade do leitor em escolher uma religião possível entre as demais $(\text { HARE..., 1974, p. } 7)^{12}$.

A segunda reportagem viria alguns meses depois, em junho do mesmo ano, descreveu que naquele "templo" teria sido instalado um "restaurante místico". A publicação da matéria parece ter sido motivada pela inauguração de um restaurante no local, chamado Sunshine Health Food's. Segundo o jornal, o estabelecimento representaria uma "tendência de consumo de cunho religioso" importada da Índia para os Estados Unidos e de lá para o Brasil.

Brishni $^{13}$, o líder e porta-voz do grupo, parecia querer apresentar uma imagem de "pureza" e de "comida saudável" para o seu recinto, por isso defendia que o restaurante seria o "único no Recife que oferece uma comida saudável”, demonstrando a maneira como gostaria que seu espaço fosse representado. O restaurante, na realidade, era estruturalmente precário e nos parece que seria mais uma tentativa de manter

\footnotetext{
${ }^{11}$ Essa representação que supunha uma imagem de hippie aos membros do Hare Krishna acompanhou por longo tempo a história desse movimento. Embora existam algumas similitudes - como a formação de comunidades alternativas, a crítica ao stablishment e ao american way of life -, as práticas de ambos os grupos se diferem substancialmente. Para uma discussão específica sobre esse assunto, confira Carvalho (2017a, p. 57-63).

${ }^{12}$ HARE Krishna tem seu templo em Olinda. Diario de Pernambuco, Recife, 05 jan. 1974, Local, Segundo Caderno, p. 7.

13 Brishni Das é californiano e foi membro do grupo dos primeiros Hare Krishna a virem dos Estados Unidos para tentar converter brasileiros ao movimento em 1973. Primeiramente ele tentou se estabelecer em São Paulo e após formar um pequeno grupo de simpatizantes, foi a Pernambuco, no mesmo ano, com três de seus seguidores para estabelecer um "templo" na Região Metropolitana de Recife.
} 
financeiramente o programa missionário do grupo. Ou, como o líder do grupo teria dito, a proposta principal parecia ser a de "discutir com todos a respeito das ideias de Krishna" (JOVENS..., 1974, p. 5) ${ }^{14}$.

Uma característica interessante nessa edição é que o líder parece se apropriar das representações geralmente feitas ao movimento Hare Krishna - presentes também nessa mesma reportagem - em relação ao pressuposto caráter "oriental" do movimento religioso. Prabhupada repetia constantemente em seus livros e palestras que esse não seria um movimento "oriental", "indiano", "Hindu", nem mesmo "religioso". Em uma perspectiva idealista, Prabhupada e seus seguidores percebiam seu movimento como sendo "transcendental" ou "espiritual"; um grupo que estaria além das designações denominacionais, culturais, geográficas e sociais (CARVALHO, 2017a, p. 83-88).

A ISKCON foi fundada nos Estados Unidos e grande parte de seus membros eram ocidentais que desenvolviam suas vidas missionárias no Ocidente, e, assim, não se viam e não simpatizavam com a ideia de serem vistos como um "movimento oriental".

Mas, utilizando-se das representações que pairavam sobre essa "religião hindu", o líder Hare Krishna aproveitou o espaço aberto pela reportagem do jornal para, "astuciosamente" 15 , realizar uma espécie de merchandising e convidar a todos para comer o "bom alimento do Oriente" (JOVENS..., 1974, p. 5)" ${ }^{16}$. A ideia de "místico Oriente primordial”, invocada pela reportagem e pela manchete que destacava o lado "místico" do restaurante, dos integrantes ou da doutrina, era reapropriada pelo religioso para estimular os leitores curiosos a visitarem o local. A noção de "religião oriental" era aqui utilizada como um convite ao "exótico" e, tanto o jornal quanto o religioso, se aproveitavam dessa representação.

No ano de 1974, o "restaurante místico" foi fechado pelo grupo missionário, que voltou para São Paulo devido às dissidências internas envolvendo os primeiros a difundirem a "consciência de Krishna" no Brasil, deixando o grupo dos devotos de Pernambuco sem uma liderança até o ano de 1977.

\footnotetext{
14 JOVENS praticam ritos orientais e instalam restaurante místico. Diário de Pernambuco, Recife, 24 jun.1974, Reportagem, Primeiro Caderno, p. 5.

${ }^{15}$ Utilizamos aqui a noção de "astúcia" de Michel de Certeau (2012, p. 74-75), quando ele define que as "astúcias" seriam formas de "resistência" ou um "modo de utilizar ou de driblar os termos dos contratos sociais". Seriam "táticas" ou uma maneira de jogar e desfazer o jogo do outro, por parte de grupos que, por não ter um lugar próprio, devem desembaraçar-se em uma rede de forças e de representações estabelecidas.

${ }^{16}$ JOVENS praticam ritos orientais e instalam restaurante místico. Diário de Pernambuco, Recife, 24 jun.1974, Reportagem, Primeiro Caderno, p. 5.
} 
Entre 1975 e 1977, o chamado "problema das seitas" tornou-se um tema frequentemente debatido pela mídia nacional e internacional e, assim, o DP abandonaria o tom "amistoso" das primeiras reportagens, ao adotar um tom alarmante para com esses grupos.

Em 1975, sem um templo que acomodasse seus membros e suas práticas, o movimento Hare Krishna passou a desenvolver suas atividades missionárias no palco das ruas do Recife. Uma reportagem do DP veiculou uma cena de pregação nas ruas da cidade, referindo-se ao movimento, pela primeira vez, como "seita". Em um tom irônico e, mesmo, provocador, a reportagem seria um tanto taxativa, indicando, talvez, que o jornalista tenha se sentido atingido pelos ataques desferidos pelos missionários. Os cinco "rapazes ainda bastante jovens" estariam ali "divulgando a seita" e "condenando o comodismo da vida moderna". O jornal descreveria a pregação como um "tumulto" e que eles estariam "espalhados" pelos "quatro cantos" da cidade - se é que cinco rapazes poderiam abarcar os "quatro cantos" de uma metrópole como Recife:

[...] Cinco rapazes que, de cabeças raspadas à semelhança dos mongóis e usando roupões, se espalham pelos quatro cantos do Recife para explicar em que consiste a filosofia do Guru Genuíno A. C. Bhaktivedanta Swami Prabhupada.

[...] Repetindo sempre as mesmas palavras usadas por todas as seitas ainda pouco conhecidas, os denominados 'Gurus' tumultuaram, ontem a tarde a Avenida Dantas Barreto, Guararapes, Rua Nova e Duque de Caxias (RAPAZES..., 1975, p. 5) ${ }^{17}$.

Os "rapazes" teriam algumas características físicas destacadas: cabeças raspadas "à semelhança dos mongóis" e usavam "roupões". Essa análise descritiva certamente proporciona um olhar atento às diferenças, invocando um olhar do "outro", separando esse do grupo dos leitores. Essa mesma narrativa do "outro" não era geralmente encontrada, por exemplo, na descrição de monges católicos pelo jornal, evidenciando um projeto, ainda inicial, de categorizar os grupos englobados como "seitas" na perspectiva de um "outro" em relação ao seu público-leitor.

No início de 1978, foi estabelecido o primeiro templo oficial da ISKCON em Recife, no bairro da Madalena, iniciando um projeto missionário ativo na cidade. Jagad Vichitra Das ${ }^{18}$ parece ter realizado um trabalho de convocação do grupo remanescente

\footnotetext{
${ }^{17}$ RAPAZES divulgam seita em Pernambuco e condenam comodismo da vida moderna. Diario de Pernambuco, Recife, 29 set. 1975, Local e Estadual, Primeiro Caderno, p. 5.

${ }^{18}$ Jagad Vichitra Das (Antônio Sérgio Lisboa Ribeiro) é discípulo de Prabhupada e um dos pioneiros do movimento Hare Krishna no Brasil. No final da década de 1970, ele foi designado como responsável institucional da ISKCON nas regiões do Norte e Nordeste e assim permaneceu até o início dos anos 2000.
} 
de simpatizantes formados entre 1974 e 1977 e uma pregação suficiente para constituir um templo que passaria a crescer em influência durante toda a primeira metade da década de 1980.

Assim, em julho de 1978, os Hare Krishna voltaram a aparecer no DP e, mais uma vez, o cenário é o das ruas do Recife. Em uma reportagem sobre as "ruas de lazer" da cidade, os Hare Krishna seriam descritos como se estivessem atuando em um palco de teatro interativo onde cada gesto e palavras descritas pareciam sugerir um espetáculo. "Que danado é isso?", "Êta bando de malandros", "Olha aqueles doidos" teriam supostamente exclamado alguns populares ao verem dois adeptos Hare Krishna cantando na Rua da Palma (RUAS..., 1978, p. A-5) ${ }^{19}$.

Formada a roda de curiosos, eles teriam se dirigido aos "espectadores" e oferecido um convite que dava direito a um jantar vegetariano em seu templo. Mas, quando os "religiosos" tiraram de sua bolsa livros sobre meditação dizendo que custavam apenas "cinco cruzeirinhos", a roda teria sido logo desfeita. Hare Krishna, comerciantes ambulantes e vendedores de "santinhos" estariam, segundo o jornal, disputando o espaço público das ruas de lazer da cidade que estariam "assumindo características próprias de uma feira” (Ibidem).

Podemos perceber que a descrição da reportagem faz uma teatralização, isto é, uma transformação das atividades missionárias em uma peça cômica em que os missionários são dispostos como brincantes, circenses de um palco interativo que visava tanto a obtenção do pagamento quanto a simpatia dos seus espectadores.

Entre o final de 1975 e meados de 1978, apenas algumas notícias nacionais ou internacionais sobre o movimento foram publicadas no DP, sendo a maior parte em tom de incompreensão e preocupação. Outros grupos passaram a ser questionados pela mídia em geral, evidenciando um crescimento do "problema das seitas" em uma conjuntura mais ampla. Essa situação foi agravada depois que um trágico evento que chocou o mundo em fins de 1978.

Ele liderou a abertura de centros da ISKCON no Recife, Fortaleza, Belém e Manaus, além da comunidade sede da instituição na região, a Fazenda Nova Vraja Dhama (Caruaru-PE).

${ }^{19}$ RUAS de lazer recifenses dão novo colorido à cidade. Diario de Pernambuco, Recife, 05 jul. 1978. Local, p. A-5. 


\section{O "perigo" das "seitas" e os "polêmicos Hare Krishna": intensificação dos conflitos e das lutas de representações}

Em novembro de 1978, os assassinatos seguidos de suicídio coletivo realizados por centenas de integrantes da comunidade do Templo do Povo na Guiana - uma organização religiosa estadunidense classificada em geral como "seita" e coordenada pelo reverendo Jim Jones - chocou a opinião pública, causando um acirramento do debate na mídia, ao estabelecer uma série de acusações e denúncias para com os grupos que indiscriminadamente fossem caracterizados como "seitas".

Após terem sido visitados por uma comitiva vinda dos Estados Unidos formada por políticos, jornalistas e familiares de membros da comunidade que investigavam denúncias contra o reverendo Jim Jones, esse teria ordenado o assassinato da comitiva que acabou matando o congressista Leo Ryan e outras quatro pessoas. Após o fato, Jones teria induzido os membros de sua comunidade a cometer suicídio coletivo, através da ingestão de cianureto diluído em suco, levando a morte de cerca de 900 pessoas da comunidade, incluindo ele mesmo. Parte das vítimas não teria cometido suicídio voluntariamente e outras teriam sido mesmo assassinadas (cf. ABBOTT, 2015).

Os jornais intensificariam então, a veiculação de reportagens com teor alarmante sobre as "seitas" e o que acontecesse em um caso específico com uma determinada "seita", logo afetaria a reputação de todas as "outras" por estarem sob o jugo da mesma classificação padronizante. O "fenômeno da multiplicação das seitas", como definiria uma matéria do DP, passou a ser tratado como uma questão de utilidade pública que deveria ser investigado e denunciado pelos jornais:

\footnotetext{
Nos últimos anos tem se registrado, no mundo inteiro, o aparecimento de estranhas seitas religiosas, em que a violência, o terror e os sacrifícios - até mesmo humanos - são uma constante. Paralelamente, também apoiados em princípios religiosos, aparecem seitas de tipo oposto, em que a passividade impera: entrega de bens materiais e suicídios em massa caracterizam esse último grupo.

[...] Desespero? Falta de fé? O Brasil não foge à regra e recentemente parece ter sido invadido pela onda da magia negra e do messianismo, além de seitas que já se tornaram muito conhecidas de nosso povo, como é o caso da Igreja da Unificação, Meninos de Deus, Cultura Racional, Evangelho Quadrangular, Krishna, Seicho-no-iê, que tem evoluído com notável êxito em nosso país



\footnotetext{
${ }^{20}$ CAVAlCANTI, Carlos. A fé está em crise? Diario de Pernambuco. Recife, 20 abr. 1980. Panorama, p. D-1.
} 
Ao se utilizar de um mecanismo como esse em que cita casos particulares de assassinato e outros crimes e, em seguida, lista nomes de grupos classificados como "seitas", o autor transferia automaticamente redes de significados e sentidos de casos particulares para atingir uma série de grupos que possuíam contextos específicos e diversos. Sem exemplificar quais as diferenças e semelhanças entre os grupos, o Hare Krishna, então, passaria, nesta matéria, a pertencer ao hall de "seitas" que poderiam cometer sacrifícios humanos (inclusive de criancinhas), suicídios em massa e praticar "magia negra", além de outros tipos de "violência".

Quando o trágico suicídio coletivo dos membros do Templo do Povo aconteceu, em novembro de 1978, todos os grupos que eram classificados como "seitas" sofreram comparações com o Templo do Povo e um clima de suspeição generalizada em relação a esses grupos se deu na América e Europa. As notícias internacionais passariam a apresentar, frequentemente, denúncias motivadas em grande parte pelo desconhecimento ou pelo desejo de deslegitimação. A descrição da teatralidade das práticas missionárias cederia lugar para o perigo que essas "seitas" representariam.

Logo após o acontecido na Guiana, prevendo uma reação do tipo "efeito dominó", o presidente do templo Hare Krishna no Recife, Jagad Vichitra se antecipou a essas discussões:

O presidente do templo Hare-Krishna no Recife, Jagaj Vicitra Das (sic), distribuiu, ontem, nota à Imprensa, lamentando os acontecimentos na colônia guianesa do "Templo do Povo" [...] e solicitando que as referências aos HareKrishna sejam em termos de religião, evitando-se as palavras "culto" e "seita".

Entendem os monges Krishna que o uso dessas palavras em relação a eles está sendo feito de modo impróprio e irresponsável, confundindo a opinião pública e comprometendo o conceito do movimento porque o vincula aos "Meninos de Deus", "Moonies", Cientologistas, Missão da Luz Divina "e agora parece que está vinculando a Sociedade Krishna ao 'Templo do Povo"”.

[...] O objetivo da nota distribuída à Imprensa é esclarecer ao povo que "nós não temos nada a ver com 'seitas e cultos"” (MONGES..., 1978, p. A-7) 21.

Segundo ele, o movimento estaria sendo "vítima de incompreensões" quanto a sua natureza religiosa, demonstrando, dessa forma, a maneira como a liderança da ISKCON gostaria que seu movimento fosse tratado ou representado.

O receio do aflito presidente não seria desprovido de fundamentos. De fato, várias reportagens seguiam, entre os anos de 1978 e 1984, fazendo esse tipo de associação e acusação.

\footnotetext{
${ }^{21}$ MONGES lamentam suicídio. Diario de Pernambuco, Recife, 05 dez. 1978. Local, p. A-7.
} 
Uma notícia internacional sobre as "seitas" informava que seu interlocutor, um especialista em "desprogramação" de membros que passaram por "seitas religiosas" (uma maneira de "desconverter" os convertidos), afirmava que:

Esse poder [para a prática de assassínio em massa ou suicídio coletivo] existe nas seitas da Igreja da Unificação, do Krishna, da Cientologia. Essas seitas são bem melhor organizadas do que o Templo do Povo. Todas elas falam em eliminar os seus inimigos (SEITA..., 1979, p. A-13, grifo nosso) ${ }^{22}$.

A generalização e a vontade de transformar todas as denominações classificadas como "seitas" em "Templos do Povo" parecia ser um recurso constante por parte da mídia que produzia representações de periculosidade sobre os novos movimentos religiosos. Nesse contexto, diversas reportagens surgiram para tentar evidenciar o perigo das "seitas". Algumas notícias tentavam colocar o movimento Hare Krishna entre a cruz e a espada, definindo a sua posição "entre a religião e a lavagem cerebral" (VERON, 1981, p. B-1) ${ }^{23}$. Outras afirmavam que "a onda do pensamento oriental" estaria promovendo uma "suave invasão" no Ocidente, inclusive no Brasil, como um sinal de alerta que visasse preparar as pessoas para uma real mudança de paradigmas na sociedade:

Com as ideias básicas e as boas intenções - a junção do pensamento oriental com o ocidental com vistas a uma sociedade humana mais justa - surgiram, tanto na Inglaterra, como nos Estados Unidos e na França e agora, no Brasil, as distorções e exageros. O propósito fundamental também se acompanha de uma mercadoria que nada tem de oriental: a venda de produtos que teriam analogia com a filosofia do Oriente, como os incensos e o patchouli, hoje comercializados até em lojas de departamento, como já o foi nos Estados Unidos, os perfumes, a literatura nem sempre sérias, as seitas espúrias como as do reverendo Moon e Hare Krishna (BARBOSA, 1982, p. B-1, grifo nosso $)^{24}$.

É interessante analisar, nessa última reportagem, como o autor acredita que seja possível existir um "pensamento oriental", como se todas as pessoas ou mestres "orientais" pensassem de uma mesma maneira ou fossem iguais e quisessem inadvertidamente subjugar ideologicamente o mundo ocidental. Também surgiriam

\footnotetext{
${ }^{22}$ SEITA da Unificação suborna deputados. Diario de Pernambuco. Recife, 03 fev. 1979. Internacional, p. A-13.

${ }^{23}$ VERON, Martine. Krishna: entre a religião e a lavagem cerebral. Diario de Pernambuco, Recife, 12 nov. 1981, Viver, p. B-1.

${ }^{24}$ BARBOSA, Manoel. A suave invasão. Diario de Pernambuco, Recife, 14 mar. 1982. Viver Domingo, p. B-1. A ideia contida nessa reportagem, em especial sobre o argumento de uma "invasão" das ideias e práticas "orientais" no Ocidente foi o que motivou o desenvolvimento de nossa Dissertação de Mestrado (CARVALHO, 2017a).
} 
livros que pretendiam mostrar "a verdadeira imagem das seitas", levando esse debate dos jornais para a literatura e vice-versa ${ }^{25}$.

Essas reportagens, cujas afirmações fortes, generalizações e acusações, muitas vezes sem quaisquer elementos comprobatórios, nos levam a crer que havia um desejo de evitar ou barrar o desenvolvimento de novos movimentos religiosos e das suas formas alternativas de religiosidade e organização social, através da veiculação de representações que depreciavam esses grupos.

Uma matéria de 1980 retrata as lutas de representações que o movimento Hare Krishna teria vivenciado no período (d'OLIVEIRA, 1980, p. C-1) ${ }^{26}$. O templo de Recife, então localizado em um sobrado alugado na Avenida 17 de Agosto, uma das regiões mais aristocráticas da cidade, indicava o relativo crescimento e a intensa atividade missionária do grupo, já que a principal fonte de renda e de manutenção da ISKCON naqueles tempos vinha da atividade de distribuição de livros nas ruas em troca de doações. A manchete "entre cânticos e preces os polêmicos Hare Krsna (sic) querem uma sociedade melhor" destacava o texto da jornalista Fernanda d'Oliveira, que investigava o desenvolvimento do movimento que chegara ao estado há alguns anos e, "como tudo que é exótico", teria chamado "a atenção".

A equipe de reportagem teria se dirigido ao templo e realizado entrevistas com os monges ali presentes. Pelo conteúdo que foi publicado nessas entrevistas, podemos entender que as "polêmicas" são em relação às representações que os membros do movimento faziam de si, de seu estilo de vida ou da religião. Vegetarianismo, práticas cotidianas dos monges (que teriam uma vida "muito simples"), seus ideais e crenças eram elementos que chamavam a atenção da equipe de repórteres. Possivelmente, o motivo de maior espanto, visto que se referiram três vezes na matéria, foi o fato de os monges Hare Krishna, até mesmo os casados, praticarem o celibato.

$\mathrm{Na}$ reportagem, parece que, novamente, um membro do movimento se utilizava de um canal disponível para veicular suas pregações, aproveitando astuciosamente um momento que poderia ser oportuno para divulgar suas próprias representações sobre o

\footnotetext{
${ }^{25}$ O livro do jornalista do Le Monde, Alain Woodroow (1979), sobre as "novas seitas", ficou bastante conhecido nesse período e diversas referências a ele podem ser observadas nos jornais do período. Cf. CARMO, Antônio Muniz O. A verdadeira imagem das novas seitas. Diario de Pernambuco. Recife, 25 nov. 1979. Literatura, p. D-6.

${ }^{26}$ d'OLIVEIRA, Fernanda. Entre cânticos e preces os polêmicos Hare Krsna querem uma sociedade melhor. Diario de Pernambuco, Recife, 30 abr. 1980, Viver, p. C-1.
} 
grupo. O monge entrevistado, Guruvagni Das ${ }^{27}$, explicava os motivos pelos quais o Hare Krishna seria "necessário à sociedade": "necessidade humana de espiritualização"; evitar os "propósitos materialistas" de muitas religiões; "dirigir melhor esta sociedade, orientando seus dirigentes numa vida mais pura"; e desenvolver o "amor a Deus".

Talvez seja pelo teor e sinceridade de suas proposições, pelos ataques ao "materialismo" ou pela diferença ("exotismo") de suas práticas e estilo de vida que eles tenham sido denominados pela matéria como "polêmicos". De qualquer forma, a autora não traça uma definição clara sobre isso na reportagem e deixa o texto em aberto para que os leitores pudessem entender por si mesmos o que viria a ser "polêmico", "exótico" e outras definições dadas aos membros e práticas Hare Krishna.

Essa segunda fase do movimento Hare Krishna em Pernambuco (1978-1984) foi marcada por constantes conflitos em termos das representações que evidenciavam projetos de construções de identidades em ascensão. Em 1984, uma reportagem evidenciou embates entre uma mãe e o templo Hare Krishna de Recife a despeito da conversão de sua filha ao movimento religioso ${ }^{28}$.

O sensacionalismo da manchete indica diretamente a periculosidade nas atividades da ISKCON na cidade, alertando a população de que a "seita" teria sido “denunciada" porque estaria "desviando a personalidade de mocinhas":

Seita denunciada

A viúva Abgail Xisto Correia denunciou o comportamento da seita Hare Krisna (sic), que modificou a personalidade de sua filha. Vera Alice, que além de perambular pelos bares, ruas e ônibus vendendo livros e incensos, "levou todas as minhas joias de ouro e objetos de inox" para o templo da organização, no bairro de Parnamirim (SEITA..., 1984a) ${ }^{29}$.

A aflição da mãe, que se dirigia ao jornal para "denunciar" a "seita", se devia ao fato de que sua filha teria se convertido ao movimento e, após se tornar maior de dezoito anos, teria saído de casa a fim de viver uma vida missionária, afirmando que "jamais se casaria".

O que parece estar em questão, de acordo com os argumentos que a mãe teria dito ao jornal, é a mudança de estilo e perspectiva de vida de sua filha, e não exatamente

\footnotetext{
${ }^{27}$ Guruvagni Das (Gilson Xavier Matos) é discípulo de Prabhupada e um dos pioneiros do movimento Hare Krishna no Brasil, tendo sido presidente do templo da ISKCON na cidade de Recife, em 1980. É filho do, então, deputado federal, Horácio Matos, do PDS baiano (entre 1975-1987).

${ }^{28} \mathrm{O}$ conjunto de fontes analisadas nessa parte inclui uma chamada na capa do jornal e uma reportagem da seção "Cidades".

${ }^{29}$ SEITA denunciada. Diario de Pernambuco, Recife, 15 jan. 1984a, Capa.
} 
a existência de crimes cometidos pelo movimento Hare Krishna. Segundo relato dela ao jornal, sua filha seria:

[...] Uma moça muito meiga, delicada, estudiosa e trabalhadeira. [...] Quando tinha 17 anos, era aplicada aluna de um bom colégio da Zona Sul e secretária do FISK de Piedade. Quando começou a frequentar com os amigos o templo Hare Krisna (sic) começaram as modificações [...] (SEITA..., 1984b, p. 15) ${ }^{30}$.

Parece que Vera teria todos os atributos de uma "mocinha" na visão de sua mãe e, mesmo, na posição do DP que, ao repetir o discurso de Abgail Xisto, inclusive nas manchetes do jornal, parecia endossar aquela representação. O Hare Krishna teria, então, "modificado" a personalidade da "mocinha" na medida em que ela frequentava o templo Hare Krishna. O espaço do local sagrado parecia um lugar a ser evitado pelo perigo que poderia oferecer: a modificação da personalidade dos jovens. A mãe faria um apelo à sociedade:

\begin{abstract}
O meu objetivo é que o seu caso [o de Vera] sirva de exemplo para outros jovens e para os pais. Sou muito religiosa e tenho fé em Deus que a minha filha um dia voltará. E receberei de porta e coração abertos. Ela é boa e muito pura. Aliás, ouço muitas pessoas acusando o Hare Krisna (sic) de antro de prostituição e tóxicos, mas não compartilho desta opinião achando, pelo contrário, que há certo "puritanismo em excesso" (Ibidem).
\end{abstract}

Fica evidente o caráter de "ameaça à harmonia familiar" que o movimento Hare Krishna estaria ocupando através das representações feitas em jornais como o DP. A desagregação das famílias como consequência das investidas de um novo movimento religioso, de suas ideias, práticas e formas de relação social diferentes, em um contexto em que a opinião pública já havia sido alertada por eventos extremos praticados pelas "seitas" (como o ocorrido na Guiana) representava uma ameaça aos valores tradicionais da família.

O que nos chama a atenção, nesse caso, além das nuances de um conflito familiar entre mãe e filha que possuíam projetos de vida conflitantes em um dado momento, são as seleções feitas pelo jornal para veicular a querela.

A reportagem não fez questão de desmentir ou pessoalizar as acusações feitas pela mãe de "lavagem cerebral", "mercenarismo" e de "matar a personalidade" de sua filha - nem mesmo duvidar se é possível "matar" a personalidade de alguém. Ao contrário, a notícia acaba "naturalizando" seu discurso, afirmando, por exemplo, na chamada feita na capa da edição daquele dia que a "seita" Hare Krishna "modificou a

\footnotetext{
${ }^{30}$ SEITA desvia personalidade de mocinhas. Diario de Pernambuco, Recife, 15 jan. 1984b, Cidade, p. 15.
} 
personalidade" da moça em questão, confirmando a capacidade e periculosidade do grupo. O Hare Krishna passar a ser tido como elemento que constitui ameaça à juventude.

Essa maneira do jornal de lidar com o Hare Krishna e os novos movimentos religiosos continuou durante toda a primeira metade da década de 1980 e passou a ter um abrandamento em suas matérias a partir da segunda metade da referida década, quando paulatinamente, o termo "seita", com todo o seu peso valorativo, passou a ser menos usado, embora ainda apareça, espaçadamente, na mídia ${ }^{31}$.

\section{Considerações finais}

O movimento Hare Krishna aportou na cidade de Recife, em fins de 1973, e já no início de 1974, adquiriu evidência nas reportagens do DP que não se caracterizaria por uma constância, mas, pela importância mais ampla no debate geral das assim denominadas "seitas". Esse espaço nos jornais certamente, não foi uma "conquista" dessas "seitas", visto que, em diversas reportagens, esses grupos sequer eram consultados sobre suas próprias definições, conhecimento, valores, identidade e história, deixando à revelia dos atores envolvidos na publicação do jornal, o papel de selecionar, definir e produzir as representações coletivas sobre os membros, as práticas e os próprios movimentos religiosos em si.

Nas reportagens que acompanhamos, entre o período de 1974 e 1984, o movimento Hare Krishna foi representado, primeiramente, como uma "religião hindu" e assim, como uma religião antiga e possível de ser acessada dentre as demais. Assim que a religião passou a desenvolver mais fortemente suas atividades missionárias nas ruas da Região Metropolitana do Recife e que o debate acerca do "problema das seitas" se intensificou nacional e internacionalmente, o Hare Krishna deixou de ser uma "religião" e passou a ser tida como algo novo, exótico, desconhecido ou simplesmente como uma "seita", englobando, nessa definição, todas as representações que eram geralmente atreladas no guarda-chuva das instituições tidas como tal.

Pudemos perceber que a longa exposição ao termo "seita" deu caráter de periculosidade ao movimento Hare Krishna (mais do que qualquer uma de suas práticas ou ideias “exóticas") e, dessa forma, o caráter investigativo e denunciativo passou a ser

\footnotetext{
${ }^{31}$ Sobre as mudanças de perspectiva dos periódicos pernambucanos no tratamento dado ao movimento Hare Krishna, confira Carvalho (2017a, p. 213-225).
} 
uma constante em relação ao movimento, fazendo circular representações que formavam um "outro" a ser evitado.

O chamado "problema das seitas" fazia parte do contexto mais amplo das mudanças pelas quais o campo religioso perpassava no Brasil durante as décadas de 1970 e 1980, com o crescimento, sobretudo, do pentecostalismo e de outras religiões que contribuíram para a perda da hegemonia católica no Brasil. Essas transformações, evidentemente, acabaram por influenciar os debates e as representações veiculadas pelos periódicos, principalmente, em regiões de forte tradição católica, como em Pernambuco no período analisado.

Certamente, muitas informações precisam ser levantadas e muitas lacunas se fazem sobre a história do movimento Hare Krishna e de outros grupos religiosos minoritários. Esse é um tema pouco explorado pela academia, todavia, esperamos que uma análise sobre as representações possa contribuir acerca dos conflitos que envolveram historicamente a inserção desse movimento e de novos grupos religiosos na sociedade brasileira. 


\section{REFERÊNCIAS}

\section{Fontes primárias}

BARBOSA, Manoel. A suave invasão. Diario de Pernambuco, Recife, 14 mar. 1982. Viver Domingo, p. B-1.

CARMO, Antônio Muniz O. A verdadeira imagem das novas seitas. Diario de Pernambuco. Recife, 25 nov. 1979. Literatura, p. D-6.

CAVAlCANTI, Carlos. A fé está em crise? Diario de Pernambuco. Recife, 20 abr. 1980. Panorama, p. D-1.

D'OLIVEIRA, Fernanda. Entre cânticos e preces os polêmicos Hare Krsna querem uma sociedade melhor. Diario de Pernambuco, Recife, 30 abr. 1980, Viver, p. C-1.

HARE Krishna tem seu templo em Olinda. Diario de Pernambuco, Recife, 05 jan.1974, Local, Segundo Caderno, p. 7.

JOVENS praticam ritos orientais e instalam restaurante místico. Diário de Pernambuco, Recife, 24 jun.1974, Reportagem, Primeiro Caderno, p. 5.

MONGES lamentam suicídio. Diario de Pernambuco, Recife, 05 dez. 1978. Local, p. A-7.

RAPAZES divulgam seita em Pernambuco e condenam comodismo da vida moderna. Diário de Pernambuco, Recife, 29 set. 1975, Local e Estadual, Primeiro Caderno, p. 5.

RUAS de lazer recifenses dão novo colorido à cidade. Diario de Pernambuco, Recife, 05 jul. 1978. Local, p. A-5.

SEITA denunciada. Diario de Pernambuco, Recife, 15 jan. 1984a, Capa.

SEITA desvia personalidade de mocinhas. Diario de Pernambuco, Recife, 15 jan. 1984b, Cidade, p. 15.

SEITA da Unificação suborna deputados. Diario de Pernambuco. Recife, 03 fev. 1979. Internacional, p. A-13.

VERON, Martine. Krishna: entre a religião e a lavagem cerebral. Diario de Pernambuco, Recife, 12 nov. 1981, Viver, p. B-1.

\section{Fontes secundárias}

ABBOTT, Catherine Barrett. The Reverend Jim Jones and Religious, Political, and Racial Radicalism in Peoples Temple. University of Wisconsin-Milwaukee. Theses and Dissertations, Paper 1037, 2015. Disponível em: 
$<$ http://dc.uwm.edu/cgi/viewcontent.cgi?article=2042\&context=etd $>$. Acesso em: 20 nov. 2016.

ADAMI, Vitor H. S. O pensamento coletivo Hare Krishna e seus modos de institucionalização: um estudo sobre comunidades globalizadas e identidades sociais. Tese (Doutorado em Antropologia). Tarragona: Universitat Rovira i Virgili, 2013.

BRYANT, Edwin; EKSTRAND, Maria. Introduction. In: BRYANT, Edwin; EKSTRAND, Maria. The Hare Krishna movement: the postcharismatic fate of a religious transplant. New York: Columbia University Press, 2004. p. 1-2.

CARVALHO, Leon Adan Gutierrez de. "A suave invasão": práticas e representações do movimento Hare Krishna em Pernambuco (1973-1996). 2017. Dissertação (Mestrado) - Universidade Federal Rural de Pernambuco, Programa de Pós-Graduação em História Social da Cultura Regional, Recife, 2017a.

CARVALHO, Leon Adan Gutierrez de. Representações, memórias e subjetividades: um estudo sobre a história do movimento Hare Krishna em Caruaru (1986-1996). Semina, Passo Fundo, v. 16, n. 1, 2017b, p. 155-169. Disponível em: $<$ http://seer.upf.br/index.php/ph/article/download/7554/4478>. Acesso em: 30 out. 2017.

CARVALHO, Leon Adan Gutierrez de. Uma movimentação estranha na Capital do Agreste: A história do Movimento Hare Krishna na cidade de Caruaru-PE (1986-2013). 2014. Monografia (Especialização) - Faculdade de Filosofia, Ciências e Letras de Caruaru, Especialização em História do Brasil, Caruaru, 2014.

CERTEAU, Michel de. A invenção do cotidiano. 1. Artes de fazer. Petrópolis: Vozes, 2012.

CHARTIER, Roger. A história cultural: entre práticas e representações. Algés: DIFEL, 2002.

CIPRIANI, Roberto; ELETA, Paula; NESTI, Arnaldo (Org.). Identidade e mudança na religiosidade latino-americana. Petrópolis: Vozes, 1997.

DUARTE, Joelma do Patrocinio. A contracultura e seus desdobramentos: novas experimentações e religiosidade New Age. 2010. Tese (Doutorado em Ciências da Religião) -Universidade Federal de Juiz de Fora, Programa de Pós-graduação em Ciências da Religião, Juiz de Fora, 2010.

FRANCO, Gilmara Yoshihara; SILVA, Márcia Pereira da. Imprensa e política no Brasil: considerações sobre o uso do jornal como fonte de pesquisa histórica. Revista História em Reflexão, Dourados, v. 4, n. 8, p. 1-11, jul./dez. 2010.

GIUMBELLI, Emerson. O fim da religião: dilemas da liberdade religiosa no Brasil e na França. São Paulo: Attar Editorial, 2002.

GUERRIERO, Silas. O Movimento Hare Krishna no Brasil: uma interpretação da cultura védica na sociedade ocidental. Rever, São Paulo, n. 1, p. 44-56, 2001. 
Disponível em: <http://www.pucsp.br/rever/rv1_2001/p_guerri.pdf>. Acesso em: 15 abr. 2016.

GUERRIERO, Silas. A diversidade religiosa no Brasil: a nebulosa do esoterismo e da Nova Era. Revista Eletrônica Correlatio, São Paulo, v. 2, n. 3, p. 128-140, abr. 2003. Disponível em: <https://www.metodista.br/revistas/revistasims/index.php/COR/article/view/1806/1791>. Acesso em: 20 abr. 2016.

GUERRIERO, Silas. Novos movimentos religiosos: o quadro brasileiro. São Paulo: Paulinas, 2006.

GUERRIERO, Silas. O movimento Hare Krishna no Brasil: a comunidade religiosa de Nova Gokula. Dissertação de Mestrado (Ciências Sociais), São Paulo: PUC (SP), 1989.

PARKER, Cristián. Seita: um conceito problemático para o estudo dos novos movimentos religiosos na América Latina. In: CIPRIANI, Roberto; ELETA, Paula; NESTI, Arnaldo (Org.). Identidade e mudança na religiosidade latino-americana. Petrópolis: Vozes, 1997.

SAID, Edward W. Orientalismo: o Oriente como invenção do Ocidente. São Paulo: Companhia das Letras, 2007.

SILVEIRA, Marcos Silva da. Hari Nama Sankirtana: etnografia de um processo ritual. Série Antropologia, n. 277. Brasília: Universidade de Brasília, 2000.

WOODROW, Alain. As novas seitas. São Paulo: Edições Paulinas, 1979. 